\title{
Let's get high
}

\author{
Craig H. Selzman, MD
}

\footnotetext{
From the Division of Cardiothoracic Surgery, Department of Surgery, University of Utah School of Medicine, Salt Lake City, Utah.

Disclosures: Author has nothing to disclose with regard to commercial support.

Received for publication March 2, 2016; accepted for publication March 4, 2016; available ahead of print March $31,2016$.

Address for reprints: Craig H. Selzman, MD, Division of Cardiothoracic Surgery, University of Utah School of Medicine, SOM 3C 127, 30 North 1900 East, Salt Lake City, UT 84132 (E-mail: craig.selzman@ @sc.utah.edu). J Thorac Cardiovasc Surg 2016;152:221-2

$0022-5223 / \$ 36.00$

Copyright (C) 2016 by The American Association for Thoracic Surgery

http://dx.doi.org/10.1016/j.jtcvs.2016.03.016
}

Nearly every talk that I give related to advanced heart failure (HF), mechanical circulatory support, and heart transplantation starts with the same (admittedly boring) story. I show some American Heart Association statistics claiming that there are 5 to 6 million people with HF and more than 500,000 new cases diagnosed each year. Within this large group is a subset of patients with advanced forms of $\mathrm{HF}$, somewhere between 50,000 and 150,000, who will die within the next 1 to 2 years unless provided a heart substitute. Then I show the classic slide from the International Society for Heart and Lung Transplantation that demonstrates an essentially flat line of cardiac transplantations in the United States that rarely exceeds 2500/year since the late 1980s. This disparity between the number of persons who could benefit from heart transplantation and the number of transplantations performed then provides the rationale for the proliferation of mechanical support.

The logical question that has been asked for decades is "Why is this line flat-why are there no more hearts transplants done now compared with 25 years ago?" Not all technology survives the period of innovation. No one drives a Ford Pinto. Although the Pinto was useful in the 1970s for carrying a 6-foot-long sub sandwich, it would also explode if another car tapped its back bumper. Cardiac transplantation does not suffer such problems as a transformative remedy for HF. It would be one thing if the results were poor, but this is far from the case. Heart transplantation remains an awesome therapy at every level, including both quality and quantity of life.

Numerous organizations, conferences, and individuals have worked tirelessly for years to increase donor awareness and organ donation. In 1995, there were 8859 organ donors associated with 2363 heart transplantations $(27 \%)$; in 2015, there were 13,710 donors associated with 2563 heart transplantations $(18 \%)$. Although heart transplantations decreased by almost 10\%, lung and pancreas transplantations more than doubled, and liver and kidney transplantations increased by $60 \%$ and $68 \%$, respectively (http:// optn.transplant.hrsa.gov). As such, our problem is not simply a supply issue.

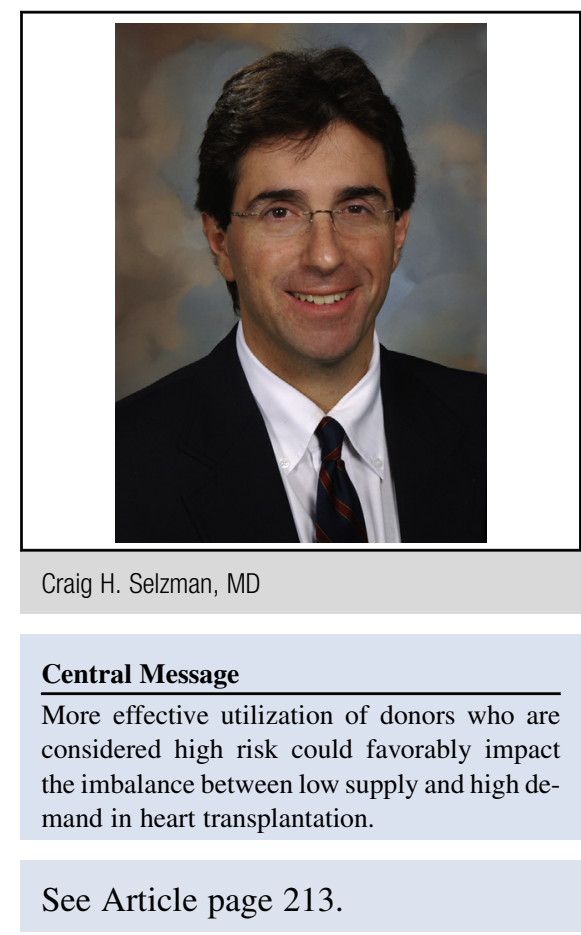

In this issue of the Journal, Gaffey and colleagues ${ }^{1}$ make a case for saying that the problem is partly ours-that is, hearts are out there, but we are not using them. This University of Pennsylvania group shares their experience using Centers for Disease Control and Prevention (CDC)-defined high-risk donors for heart transplantation. They describe 55 patients from a total of 367 patients transplanted over a 6-year period. This represents a large single-institution experience that compliments their previous large data inquiry using the United Network for Organ Sharing (UNOS) dataset. ${ }^{2}$ The authors reveal that only 1 patient out of 55 patients seroconverted to hepatitis $\mathrm{C}$ virus. Importantly, there were no issues with graft function (similar to the findings of a pediatric UNOS study as well). ${ }^{3}$ Although some published data extrapolate the risk of transmission of disease in organ transplantation, this is the first series to examine this issue with adult heart transplantation.

Several limitations must be recognized when drawing conclusions from this study, especially given that this is a singleinstitution experience and not a large data plunge like the authors' previous UNOS paper. ${ }^{1}$ There is no information on how serologies were tested (nucleic acid testing vs antibody). The former is well known to decrease the potential window for seroconversion, thereby giving many physicians

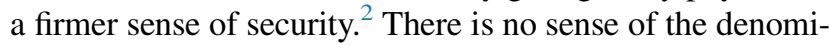
nator of high-risk donor offers; that is, how many CDC 
high-risk donors were offered versus how many were actually accepted. This plays into the possibility of selection bias by the institution. ${ }^{3}$ Importantly, there is no information as to the reason why the donor met high-risk status. The risk of disease transmission varies greatly when comparing, for example, commercial sex workers, intravenous drug abusers, and hemophiliacs. This level of granularity might prove useful in the decision making process.

A recent article in the Journal detailed the successful attempts by the University of Washington group to enhance donor utilization. ${ }^{4}$ This manuscript was accompanied by an excellent editorial by Nick Smedira, who made some great points that are worth reiterating. ${ }^{5}$ Although the term "CDC high risk" has value, the semantics of this designation is misleading. Despite the advent of nucleic acid testing, the mere mention of CDC high risk provokes an emotional response that is not necessarily supported scientifically.

To gain a little local perspective, I asked our organ provider organization (Intermountain Donor Services) to pull the data on our use of donor hearts. Over the last 3 years, $17 \%$ to $26 \%$ of our donors were designated as CDC high risk. Of those, $32 \%$ to $39 \%$ underwent transplantation. In comparison, the rate of use of non-CDC high-risk donors was between $28 \%$ and $42 \%$. The reasons for not using organs (eg, size, antibodies) are mostly similar. Although one could question our overall donor efficiency, it appears that, at least within our service area, we appear to be fairly agnostic to the CDC designation. The work of Gaffey and colleagues helps me sleep better in light of our anecdotal experience.

Summarily, the authors are telling us that the use of CDC high-risk donors is not hurting our patients. One of the nice points highlighted in this manuscript is the importance of pretransplantation counseling and informing patients about this cohort of donors such that these decisions become much easier at $2 \mathrm{am}$. Ultimately, each program and each recipient will need to determine their threshold for using these donors; however, if we want to close the gap between supply and demand, we will need to get (CDC) high.

\section{References}

1. Gaffey AC, Doll SL, Thomasson AM, Venkataraman C, Chen CW, Goldberg LR, et al. Transplantation of "high-risk" donor hearts: implications for infection. J Thorac Cardiovasc Surg. 2016;152:213-20.

2. Gaffey AC, Cucchiara AJ, Goldberg LR, Blumberg EA, Acker MA, Atluri P. Transplantation of Centers for Disease Control "high-risk" donor hearts does not adversely impact long-term outcomes in adults. J Card Fail. 2016 [Epub ahead of print].

3. Sahulee R, Lytrivi ID, Savla JJ, Rossano JW. Centers for Disease Control "high-risk" donor status does not significantly affect recipient outcome after heart transplantation in children. J Heart Lung Transplant. 2014;33:1173-7.

4. Smith JW, O'Brien KD, Dardas T, Pal JD, Fishbein DP, Levy WC, et al. Systematic donor selection review process improves cardiac transplant volumes and outcomes. J Thorac Cardiovasc Surg. 2016;151:238-43.

5. Smedira NG. Saying yes or saying no! J Thorac Cardiovasc Surg. 2016;151: 243-4. 